\title{
Cardiothoracic
}

Transplantation

\section{Prevalence and risks of allosensitization in HeartMate left ventricular assist device recipients: The impact of leukofiltered cellular blood product transfusions}

\author{
Stavros G. Drakos, MD, James C. Stringham, MD, ${ }^{a, c, d}$ James W. Long, MD, PhD, a,b Edward M. Gilbert, MD, ${ }^{a, d}$ \\ Thomas C. Fuller, PhD, ${ }^{a, d}$ Beverly K. Campbell, RN, ${ }^{a, b}$ Benjamin D. Horne, PhD, MPH, ${ }^{a, b}$ Mary E. Hagan, FNP, ${ }^{a, c}$ \\ Karl E. Nelson, RN, ${ }^{a, b}$ Judy M. Lindblom, MT, ${ }^{b}$ Patty A. Meldrum, RN, ${ }^{d}$ Joanne F. Carlson, MS, NP, ${ }^{*, a, d}$ \\ Stephanie A. Moore, MD, ${ }^{a, b}$ Abdallah G. Kfoury, MD, ${ }^{a, b}$ and Dale G. Renlund, MD
}

From the Utah Transplantation Affiliated Hospitals (UTAH) Cardiac Transplant Program, ${ }^{\text {a }}$ LDS Hospital, ${ }^{\text {b }}$ Salt Lake Veteran's Affairs Medical Center, ${ }^{c}$ and the University of Utah School of Medicine, ${ }^{\mathrm{d}}$ Salt Lake City, Utah.

Received for publication June 7, 2006; revisions received Oct 4, 2006; accepted for publication Nov 9, 2006.

Address for reprints: James C. Stringham, MD, Division of Cardiothoracic Surgery, University of Utah School of Medicine, 30 N 1900 E, Suite 3C127, Salt Lake City, UT 84132 (E-mail: jamesstringham@msn. com).

*Deceased.

J Thorac Cardiovasc Surg 2007;133:1612-9 $0022-5223 / \$ 32.00$

Copyright () 2007 by The American Association for Thoracic Surgery

doi:10.1016/j.jtcvs.2006.11.062
Objective: Allosensitization of left ventricular assist device recipients has been associated with perioperative transfusion of cellular blood products. The relative sensitizing contribution of leukofiltered cellular blood products, however, remains unclear. We investigated the pattern of sensitization in left ventricular assist device recipients in relation to cellular blood product transfusions received.

Methods: Seventy-one consecutive nonsensitized recipients of the HeartMate left ventricular assist device (Thoratec Corporation, Pleasanton, Calif) as a bridge to transplantation were reviewed. Panel-reactive HLA antibody levels at consecutive times after device implantation were correlated with perioperative cellular blood product transfusions.

Results: Fifty-four patients received leukofiltered cellular blood products (transfused), whereas 17 patients received only fresh-frozen plasma (nontransfused). Among nontransfused patients, 58.8\% (10/17) became sensitized during mechanical support, versus $35.2 \%$ of transfused patients $(19 / 54, P=.15)$. There was a trend toward more sensitization during the 12 weeks after device placement in nontransfused patients. Kaplan-Meier analysis revealed significantly more sensitization in nontransfused patients than in transfused patients, despite equal rates of transplantation $(P=.05)$. A dose-response analysis revealed significant trends toward less sensitization and lower peak panel-reactive antibody level with more cellular blood product transfusions $(P=.04)$. Multivariate Cox regression revealed only increasing transfusions to be associated with a reduced risk of sensitization (hazard ratio $0.18, P=.01$ ).

Conclusions: Sensitization becomes more prevalent with increasing length of support. Avoidance of perioperative leukocyte-filtered cellular blood product transfusions does not decrease the incidence or degree of HLA sensitization. Conversely, cellular blood product transfusions may be associated with lessened alloimmunization and may mitigate the sensitization seen in recipients of the HeartMate left ventricular assist device as a bridge to transplantation. 
$\mathrm{T}$ he advent of mechanical assistance for the failing left ventricle has been lifesaving for patients awaiting heart transplantation. As the number of patients listed for transplantation has risen in an era of fixed or declining donor availability, many have required mechanical ventricular assistance as a bridge to transplantation. Since approval for clinical use, left ventricular assist devices (LVADs) have contributed to the progressive decline in death rate on the United Network for Organ Sharing heart transplant waiting list, which has decreased from 274 to 162 deaths per 1000 patient-years at risk in the period from 1994 to $2003 .{ }^{1}$ LVADs have allowed many patients to survive to successful transplantation who otherwise would have either died or become unsuitable transplant candidates. ${ }^{2}$

Despite this success in bridging strategy, it has become apparent that many LVAD-supported heart transplant candidates have circulating anti-HLA antibodies develop, with potential donor reactivity, and show elevation of panelreactive antibody (PRA). ${ }^{3,4}$ The existence of preformed antibodies delays cardiac transplantation, decreases the potential donor pool because of difficulty in identifying a suitable crossmatch-negative donor, and can exact a significant emotional toll on patients as the wait for a compatible donor goes on and on. Furthermore, sensitized patients have been shown to be at higher risk for posttransplantation rejection, morbidity, and mortality. ${ }^{5-7}$

Patients who require mechanical support often receive multiple transfusions because of coagulopathy from hepatic congestion or poor hepatic function, bleeding caused by adhesions from previous surgery, or preoperative anticoagulation. Sensitization of the LVAD recipient has been thought to be associated with the perioperative transfusion of cellular blood products, which are often required. ${ }^{3,4,8} \mathrm{We}$ have had success in limiting or completely avoiding the amount of cellular blood products transfused in this patient population. ${ }^{9}$ In this study we investigated the relative contribution of cellular blood product transfusion to HLA allosensitization in LVAD recipients bridged to cardiac transplantation.

\section{Materials and Methods}

The clinical and laboratory records were reviewed for 84 consecutive patients with heart failure who underwent implantation of either the IP (pneumatic) or VE (vented electric) HeartMate LVAS (Thoratec Corporation, Pleasanton, Calif) as a bridge to transplantation from May 30, 1993, to August 6, 2002. All patients provided informed consent for collection of data used in this study, and the institutional review committee from each institution approved such data collection for research. Serum samples from each patient were collected before LVAD implantation and at intervals of 2 to 4 weeks thereafter; samples underwent PRA determination against a panel of donor lymphocytes representing the spectrum of HLA specificities by either the antiglobulin-augmented, complementdependent lymphocytotoxicity assay or flow cytometry, methods that were used with equal frequency and found to be comparable

$$
\begin{aligned}
& \text { Abbreviations and Acronyms } \\
& \begin{aligned}
\text { CI } & =\text { confidence interval } \\
\text { FFP } & =\text { fresh-frozen plasma } \\
\text { HR } & =\text { hazard ratio } \\
\text { LVAD } & =\text { left ventricular assist device } \\
\text { PRA } & =\text { panel-reactive antibody } \\
\text { pRBCs } & =\text { packed red blood cells } \\
\text { Q1 } & \text { first quartile } \\
\text { Q2 } & =\text { second quartile } \\
\text { Q3 } & =\text { third quartile } \\
\text { Q4 } & \text { fourth quartile }
\end{aligned}
\end{aligned}
$$

in detecting HLA antibody. ${ }^{9}$ All samples were treated with dithiothreitol to remove immunoglobulin M sensitivity. A PRA greater than $10 \%$, indicating antibody reactive against antigen in $>10 \%$ of tested samples, was accepted as defining HLA allosensitization. All sensitized LVAD recipients underwent a negative prospective crossmatch before transplantation. PRA levels indicating the degree of sensitization were correlated with perioperative transfusions of cellular blood products, defined as either packed red blood cells (pRBCs) or platelets. The perioperative period was defined from LVAD implantation to 4 weeks after implantation.

Thirteen patients found to have either an elevated PRA $(>10 \%$, $\mathrm{n}=10)$ or no PRA measurement before LVAD implantation $(\mathrm{n}=$ 3) were excluded from further analysis. This report consists of analysis of the remaining 71 patients. The transfused group $(\mathrm{n}=$ 54) comprised patients receiving perioperative cellular blood products. The nontransfused group $(\mathrm{n}=17)$ did not receive any cellular blood products. All in the nontransfused group, however, did receive perioperative fresh-frozen plasma (FFP). All cellular blood products were leukocyte filtered with standard, commercially available filters. Indications for transfusion included a hematocrit lower than $25 \%$ for pRBCs or continued bleeding with a platelet count lower than 100,000 cells/ $\mu \mathrm{L}$ for platelets. In the nontransfused group, patients were given FFP to correct coagulopathy and allowed to have a lower hematocrit if right ventricular function remained adequate and mixed venous oxygen saturation remained above $60 \%$, as per our previously published protocol. ${ }^{9}$

Results of continuous variables are expressed as the mean \pm SD. Comparisons between the two groups were made with the $\chi^{2}$ test, Fisher exact test, and Student $t$ test. Rates of sensitization and transplantation across time were determined by Kaplan-Meier methods and compared with the log-rank test. The effect of transfusion quantity on sensitization was determined by dividing the entire patient population into four equal quartiles according to the combined number of units of cellular blood products (either pRBCs or platelets) received. The first quartile (Q1) included 17 patients who received no cellular blood products. The second quartile (Q2) received 1 to 6 units of cellular blood products $(\mathrm{n}=$ $18)$, the third quartile (Q3) received 7 to 15 units $(n=18)$, and the fourth quartile $(\mathrm{Q} 4)$ received 16 or more units $(\mathrm{n}=18)$. Differences in PRA across quartiles were assessed with the KruskalWallis test, and differences between individual quartiles were evaluated by the Wilcoxon-Mann-Whitney test. Comparisons were also performed for categories of peak PRA, sensitized 
TABLE 1. Patient characteristics

\begin{tabular}{|c|c|c|c|}
\hline & Cellular transfusion $(n=54)$ & No cellular transfusion $(n=17)$ & $P$ value \\
\hline \multicolumn{4}{|l|}{ Transfusion requirements } \\
\hline Fresh-frozen plasma (units) & $12.5 \pm 8.0(0-34)$ & $9.9 \pm 5.1(4-19)$ & \\
\hline Packed red blood cells (units) & $10.9 \pm 10.0(0-45)$ & & \\
\hline Platelets (units) & $3.3 \pm 3.3(0-12)$ & & \\
\hline Age (y) & $50.2 \pm 11.1$ & $48.8 \pm 15.8$ & .69 \\
\hline \multicolumn{4}{|l|}{ Cardiac diagnosis (No.) } \\
\hline Idiopathic dilated cardiomypathy & 15 & 7 & .46 \\
\hline Coronary artery disease & 35 & 9 & .32 \\
\hline Other & 4 & 1 & $>.999$ \\
\hline Sex (male/female) & $49: 5$ & $16: 1$ & $>.999$ \\
\hline Duration of support (d) & $181.6 \pm 171.2$ & $166.7 \pm 155.3$ & .75 \\
\hline Time to transplantation (d) & $178.9 \pm 182.8$ & $163.9 \pm 167.1$ & .77 \\
\hline Survival to transplantation (No.) & $50 / 54(92.6 \%)$ & $16 / 17(94.1 \%)$ & $>.999$ \\
\hline Previous median sternotomy (No.) & $18 / 54(33.3 \%)$ & $6 / 17(35.3 \%)$ & $>.999$ \\
\hline Pre-LVAD total bilirubin (mg/dL) & $1.8 \pm 1.5$ & $1.6 \pm 1.1$ & .65 \\
\hline LVAD replacements (No.) & $5 / 54(9.3 \%)$ & $3 / 17(17.6 \%)$ & .39 \\
\hline
\end{tabular}

Data represent mean \pm SD (with ranges in parentheses as appropriate) except as noted. LVAD, Left ventricular assist device.

$(>10 \%)$, and highly sensitized $(>90 \%)$ according to transfusion quartile with the $\chi^{2}$ statistic and the Armitage test for linear trend.

Univariate and multivariate Cox regression analyses were used to assess the impact of patient-related and transfusion-related variables on the risk of sensitization, with censoring of time-related events such as death or transplantation. Conditional stepwise and forced variable entry was used to assess confounding and model fit. Variables included patient age, duration of support, previous sternotomy, heart failure etiology, and quartile of either combined transfusion quantity or separate component quantity. Age was modeled as a continuous variable. Separate component quartiles were defined for $\mathrm{pRBCs}$ (Q1 0 units, $\mathrm{n}=18$, Q2 1-5 units, $\mathrm{n}=$ 15, Q3 6-13 units, $\mathrm{n}=19, \mathrm{Q} 4 \geq 14$ units, $\mathrm{n}=19$ ), platelets (Q1 0 units, $\mathrm{n}=28$, Q2 1 unit, $\mathrm{n}=11$, Q3 2-4 units, $\mathrm{n}=16, \mathrm{Q} 4 \geq$ 5 units), and FFP (Q1 $\leq 6$ units, $\mathrm{n}=21$, Q2 7-12 units, $\mathrm{n}=14$, Q3 13-16 units, $\mathrm{n}=20, \mathrm{Q} 4 \geq 17$ units, $\mathrm{n}=16$ ).

\section{Results}

The transfusion requirements and demographic characteristics of each group are summarized in Table 1. Of the 71 patients studied, 54 received cellular blood products (transfused group); the remaining 17 received no cellular blood products (nontransfused group). All patients in the nontransfused group and all but 4 patients in the transfused group received perioperative transfusions of FFP. The age, sex, cardiac diagnosis, duration of mechanical support, waiting time to transplantation, survival to transplantation, incidence of previous sternotomy, and preimplantation total bilirubin as a marker of heart failure severity were similar between groups.

During the wait for transplantation, there was a trend toward less overall sensitization in the transfused group, although this did not reach statistical significance. In the transfused group $35.2 \%$ of patients (19/54) became sensi- tized (PRA $>10 \%$ ) during mechanical support, compared with $58.8 \%(10 / 17)$ in the nontransfused group $(P=.15)$. A PRA greater than $90 \%$ was seen in $16.7 \%$ patients $(9 / 54)$ in the transfused group versus $23.5 \%$ patients $(4 / 17)$ in the nontransfused group $(P=.5)$.

A similar trend was seen in the mean PRA at consecutive time points after LVAD implantation (Figure 1). The transfused group had mean PRAs of $7.9 \% \pm 22 \%$ $(\mathrm{n}=51), 10.9 \% \pm 24.5 \%(\mathrm{n}=40), 16.9 \% \pm 29.8 \%(\mathrm{n}=$ $43)$, and $24.6 \% \pm 36.9 \%(\mathrm{n}=34)$ at $4,6,8$, and 12 weeks after implantation, respectively. The nontransfused group had mean PRAs of $8.5 \% \pm 17.7 \%(\mathrm{n}=15)$, $16 \% \pm 29.6 \%(\mathrm{n}=11), 35.1 \% \pm 39.1 \%(\mathrm{n}=12)$, and

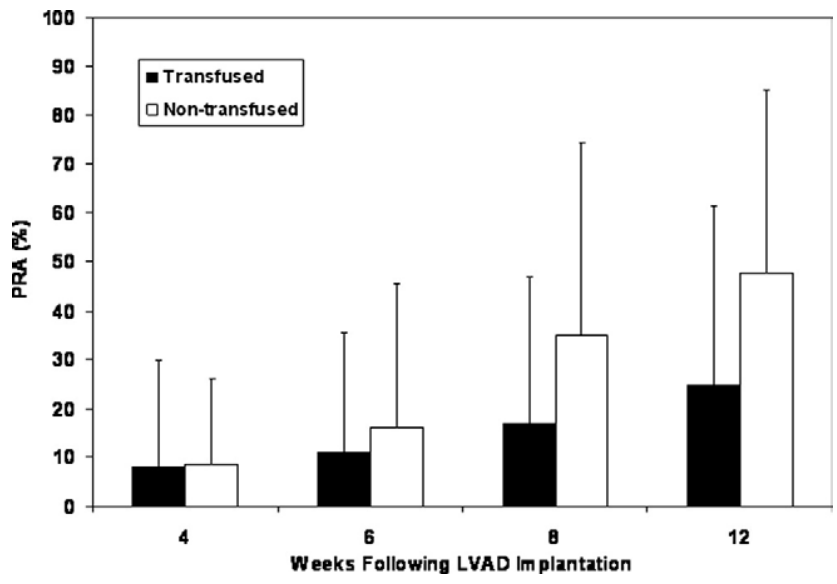

Figure 1. Time course of development of sensitization (panel reactive antibody $[P R A]>10 \%$ ) after left ventricular assist device (LVAD) implantation. 


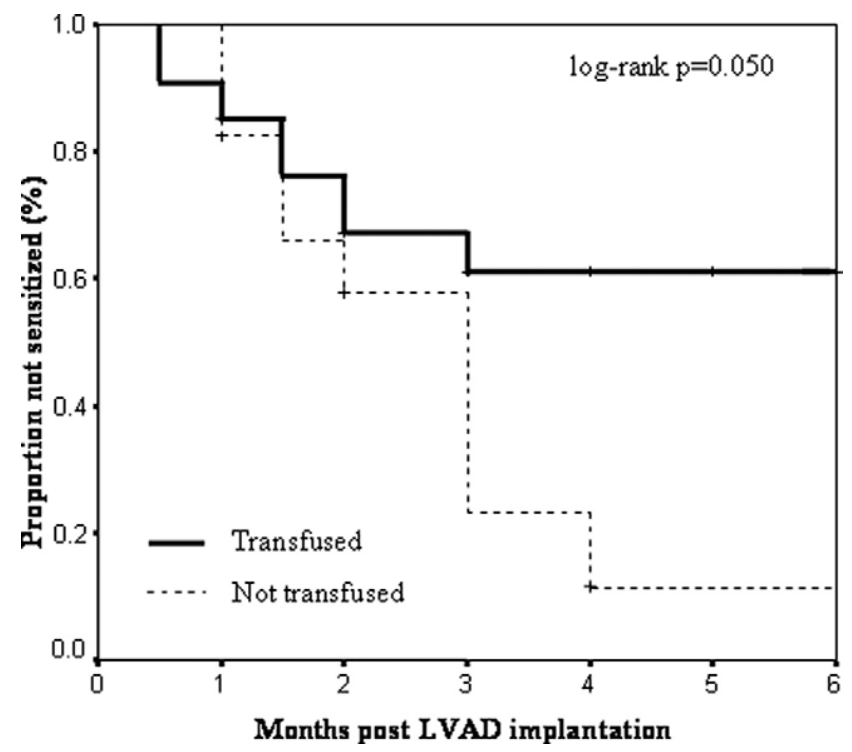

Figure 2. Kaplan-Meier analysis of incidence of sensitization among left ventricular assist device (LVAD) recipients who either did or did not receive cellular blood product transfusions.

$47.6 \% \pm 37.5 \%(\mathrm{n}=9)$ at $4,6,8$, and 12 weeks after implantation, respectively (difference not significant). There was no difference between the peak PRA reached in the transfused group and that in the nontransfused group $(66.7 \% \pm 31.7 \%$ transfused vs $71.1 \% \pm 24.3 \%$ nontransfused, $P=.70)$.

Among patients becoming sensitized, there was a trend toward earlier sensitization with transfusions $(5.4 \pm 3.2$

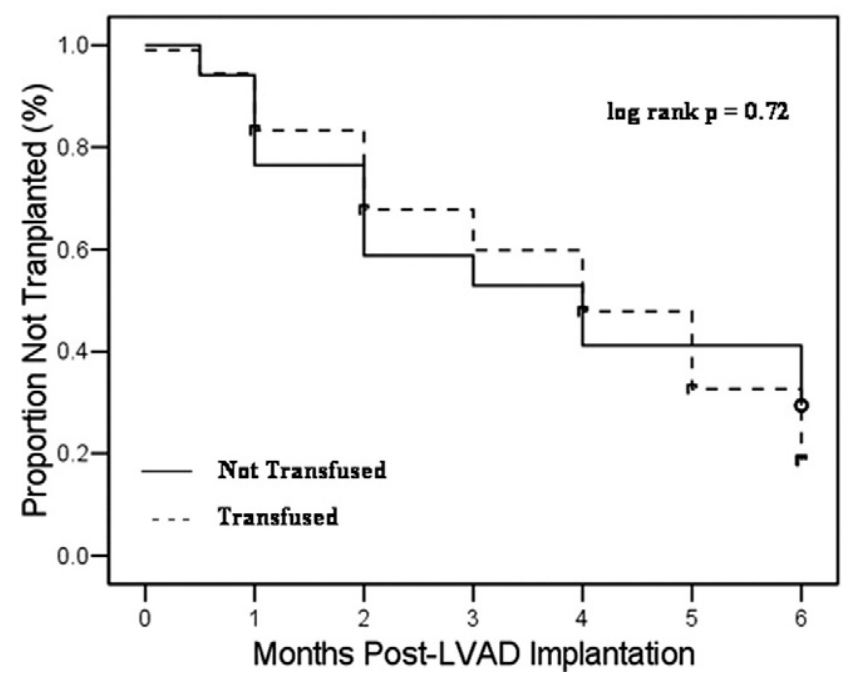

Figure 3. Kaplan-Meier analysis of incidence of transplantation among left ventricular assist device (LVAD) recipients who either did or did not receive cellular blood product transfusions. weeks in the transfused group vs. $8.4 \pm 4.3$ weeks in the nontransfused group, $P=.08)$, as well as an earlier peak PRA in patients receiving transfusions (12.1 \pm 7.9 weeks transfused vs $16.8 \pm 8.8$ weeks nontransfused, $P=.16$ ).

When the groups were analyzed by Kaplan-Meier methods for freedom from sensitization, a larger proportion of the nontransfused group became sensitized during support relative to the transfused group, reaching significance 3 months after LVAD implantation $(P=.05$, Figure 2). This result could be skewed by the rate of transplantation, because the actuarial analysis censored patients not only for sensitization but also for transplantation (because after transplantation patients were no longer considered at risk). Theoretically, if more patients in a particular group underwent transplantation early, before becoming sensitized, that group would eventually show a larger percentage of sensitized patients still waiting for transplantation. To help avoid this confusion, we compared the rate of transplantation between the two groups and found it to be nearly identical (Figure 3). When the rate of transplantation was compared between sensitized and nonsensitized patients, however, there was a significant delay in transplantation for those with PRA greater than $10 \%(P<$ .001; Figure 4).

To elucidate the impact of transfusion quantity on allosensitization, the entire patient population was divided into equal quartiles according to the combined units of cellular blood products received. The proportions of sensitized and highly sensitized (PRA $>90 \%$ ) patients and peak PRAs for each quartile are summarized in Table 2. The duration of mechanical support was similar among the quartiles. The peak PRA of the massively transfused subgroup

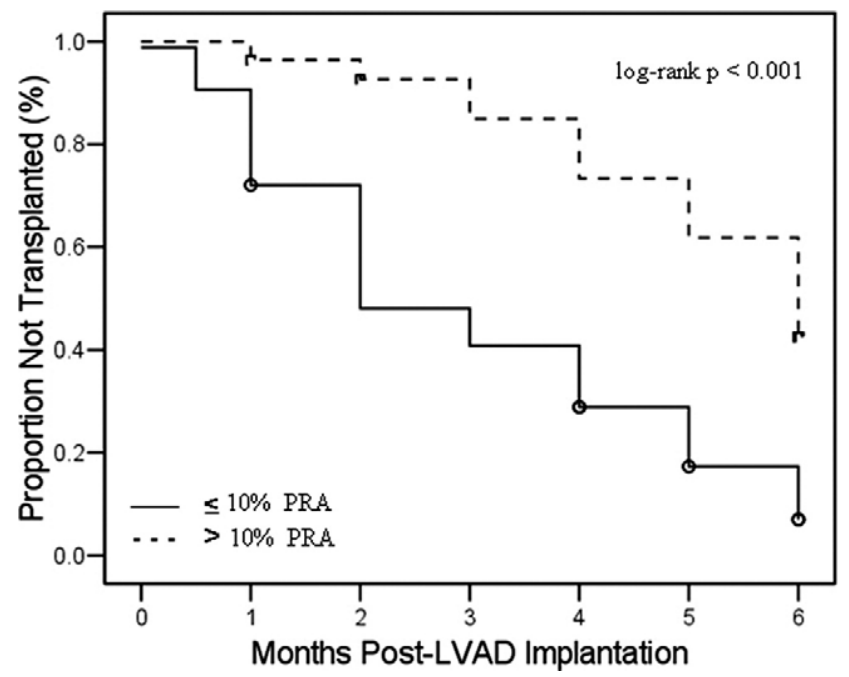

Figure 4. Kaplan-Meier analysis of rates of transplantation in left ventricular assist device recipients who either did (panel reactive antibody $>10 \%$ ) or did not acquire allosensitization. 
TABLE 2. Effect of cellular transfusion quantity on sensitization

\begin{tabular}{lccccc}
\hline Quartile & $\mathbf{n}$ & Support (d) & Peak PRA (\%) & $\begin{array}{c}\text { Nonsensitized } \\
\text { (PRA } \leq \mathbf{1 0} \%)\end{array}$ & $\begin{array}{c}\text { Highly sensitized } \\
\text { (PRA }>\text { 90\%) }\end{array}$ \\
\hline Quartile 1 (none) & 17 & $166 \pm 155$ & $42 \% \pm 40 \%$ & $41 \%$ & $18 \%$ \\
Quartile 2 (1-6 units) & 18 & $198 \pm 170$ & $39 \% \pm 43 \%$ & $44 \%$ & $28 \%$ \\
Quartile 3 (7-15 units) & 18 & $161 \pm 192$ & $19 \% \pm 34 \%$ & $72 \%$ & $11 \%$ \\
Quartile 4 ( $\geq 16$ units) & 18 & $168 \pm 156$ & $9 \% \pm 25 \% *$ & $83 \% \dagger$ & $6 \%$ \\
\hline
\end{tabular}

$P R A$, Panel-reactive antibody. ${ }^{*} P=.02$, quartile 4 versus quartile $1 . \dagger P=.009$, quartile 4 versus quartile 1.

(Q4) was significantly lower than the peak PRA in the not transfused (Q1) subgroup $(P=.02)$. Differences in peak PRA level of all four quartiles were also found to be significant $(P=.02)$.

Analysis of the proportion of nonsensitized and highly sensitized patients in each quartile showed a significant stepwise linear trend $(P=.04)$, suggesting that patients with higher transfusion requirements actually had less sensitization. Only $41 \%$ in the nontransfused group (Q1) remained free of sensitization, compared with $83 \%$ of the massively transfused patients $(\mathrm{Q} 4, P=.009)$, whereas $18 \%$ of $\mathrm{Q} 1$ patients became highly sensitized compared with only $6 \%$ of those in Q4 $(P=.25)$.

A Cox regression analysis was used to assess the effects of patient-related and transfusion-related variables on the risk of sensitization. With univariate analysis, only quartile of transfusion (Q1 vs Q4, $P=.013$ ) was associated with sensitization. Factors not associated with increased risk of sensitization included age $(P=.69$, hazard ratio [HR] 0.94/decade, $95 \%$ confidence interval [CI] 0.70-1.43), sex $(P=.85$, HR $0.87,95 \%$ CI 0.21-3.66), duration of support at least 6 weeks $(P=.24$, HR 3.39, 95\% CI $0.45-2.54)$, previous sternotomy $(P=.46$, HR $0.72,95 \%$ CI 0.30 1.72), and heart failure etiology other than coronary artery disease (idiopathic $P=.71, \mathrm{HR}=0.85,95 \% \mathrm{CI}=0.36-2.03$, other $P=.69$, HR $1.35,95 \%$ CI $0.31-5.83)$. Multivariate regression (Table 3 ) confirmed a reduced risk of sensitization at each quartile of increasing transfusion.

Analysis of the component-specific effect of blood products on sensitization was difficult because of the small numbers involved and significant overlap of blood products used, making meaningful statistical comparisons difficult. In the nontransfused group, those becoming sensitized (10/ $17,59 \%$ ) received a mean of 9.5 units of FFP, whereas those remaining nonsensitized received a mean of 11.0 units of FFP (difference not significant). Only 2 patients received pRBCs and no FFP or platelets; 1 received 3 units and the other 16 units. Both remained nonsensitized at transplantation 1 and 6 months later, respectively. Eleven patients received pRBCs but no platelets ( 8 received FFP), and 4 (36\%) became sensitized. Only 1 patient received platelets but no pRBCs and had become sensitized by 6 weeks of support. Conversely, 9 patients received 6 or more units of platelets (as well as multiple units of pRBCs), and only 2 (22\%) became sensitized.

Multivariate Cox regression analysis examining each component separately in four quartiles according to transfusion volume showed the risk of sensitization was lowest in $\mathrm{Q} 4$ versus $\mathrm{Q} 1$, with the effect from $\mathrm{pRBCs}$ being the strongest. Because of significant exposure to both $\mathrm{pRBCs}$ and either platelets or FFP, however, the major benefit may have been from exposure to pRBCs (Table 3).

\section{Discussion}

Bridging to cardiac transplantation with LVAD support has become a widely accepted method of heart failure treatment for those who would otherwise not survive. Many of these patients, however, eventually acquire circulating antibody with HLA reactivity. There are few data on the true character of this antibody, except that it is often highly reactive

TABLE 3. Multivariate Cox regression analysis of risk of sensitization

\begin{tabular}{|c|c|c|c|}
\hline Variable & Hazard ratio & 95\% Confidence interval & $P$ value \\
\hline \multicolumn{4}{|l|}{ Combined transfusion quartile (vs quartile 1) } \\
\hline Quartile 2 (1-6 units) & 1.09 & $0.45-2.63$ & .85 \\
\hline Quartile 3 (7-15 units) & 0.43 & $0.15-1.25$ & .12 \\
\hline Quartile 4 ( $\geq 16$ units) & 0.18 & $0.05-0.67$ & $.01^{*}$ \\
\hline \multicolumn{4}{|l|}{ Individual components (vs quartile 1 ) } \\
\hline Packed red blood cell quartile 4 ( $\geq 14$ units) & 0.17 & $0.05-0.61$ & $.007^{*}$ \\
\hline Platelets quartile 4 ( $\geq 5$ units) & 0.23 & $0.06-0.79$ & $.020^{*}$ \\
\hline Fresh-frozen plasma quartile 4 ( $\geq 17$ units) & 0.35 & $0.11-1.10$ & .07 \\
\hline
\end{tabular}

*Statistically significant. 
on standard HLA class I antibody screens, sometimes reaching $100 \%$. In our experience, rarely is antibody to HLA class II antigens observed (unpublished data). Sensitized LVAD recipients may wait years for a compatible donor. Only limited success has been achieved with protocols of desensitization, ${ }^{10}$ which are neither universally successful nor standardized and expose the patient to invasive procedures and costly medications with significant risks and potential side effects. Furthermore, sensitization has been implicated in increasing the risks of acute rejection and posttransplantation death. ${ }^{5-7}$

In patients who have not been previously sensitized, the major factor giving rise to antibody production is commonly thought to be the number of transfusions received at the time of LVAD implantation. ${ }^{3,4,8}$ Leukocytes contained in cellular blood product transfusions have long been implicated as a source of sensitization. Fauchet and colleagues ${ }^{11}$ showed that after transfusions of nonleukofiltered blood products during cardiac surgical procedures, $33.6 \%$ of male and $64.3 \%$ of female patients acquired anti-HLA antibodies. ${ }^{11}$ Methods of leukofiltration have been more recently adopted to decrease the alloimmunizing effect of transfusions. Leukocyte reduction filters have been shown to decrease the total leukocyte count to less than $5 \times 10^{6}$ per blood component and to be effective at reducing the incidence of sensitization in patients without previous exposure. ${ }^{12}$

In this study, we attempted to characterize the patterns of and contributing factors to post-LVAD sensitization when leukofiltered blood products are used. We found that transfusions of leukofiltered cellular blood products did not worsen sensitization relative to patients who received no such transfusions. Unexpectedly, we found a trend toward a higher rate of sensitization in nontransfused patients and noted that nontransfused patients became sensitized more frequently when studied across time by actuarial methods. We initially supposed that this was because more nonsensitized patients in the nontransfused group underwent transplantation early, thus eliminating nonsensitized patients from the cohort and increasing the relative proportion of sensitized patients. On further analysis, however, the rate of transplantation was found to be identical between these two groups.

We also paradoxically found lower sensitization among patients who received more transfusions of cellular blood products, with the lowest incidence occurring among those receiving the highest numbers of transfusions. This linear trend reached significance despite the small numbers of patients in each quartile. Further analysis by multivariate Cox regression failed to show any significant impact of age, sex, LVAD support longer than 6 weeks, previous surgery, or heart failure etiology. Although sensitization increased with time, only increasing amounts of cellular blood product transfusion were associated with a progressive risk reduction for sensitization. Examination for a component- specific effect showed exposure to pRBCs to have the strongest protective effect against sensitization.

Our findings suggest that strategies of withholding perioperative transfusions in LVAD recipients have no clear advantage in reducing sensitization as long as leukofiltered blood products are used. This is not to say, however, that transfusion with impunity is acceptable in this population. Our data do not show that leukofiltered blood products do not cause alloimmunization. HLA sensitization may still occur as a result of transfusion. Transfusions also have other adverse sequelae, such as pulmonary dysfunction, increased risk of right heart failure, ${ }^{13}$ and increased risk of infection. ${ }^{14}$ Transfusions should be given judiciously and only when necessary.

The counterintuitive hypothesis that transfusion may result in less sensitization will require more careful study in larger numbers of patients. It is, however, consistent with the known immunomodulatory effects of transfusions. ${ }^{15,16}$ Pretransplantation transfusions have been suggested as a means for improving kidney allograft survival because of their immunosuppressive effect. ${ }^{17}$ Leukofiltration has been reported to decrease or eliminate this immunosuppressive effect. ${ }^{18}$ Our data suggest that an immunosuppressive effect of transfusions may still be present even after leukofiltration, although larger numbers of leukofiltered cellular blood products may be necessary to limit sensitization. Perhaps this may occur through a critical mass of leukocytes that escape filtration and are passed on to the recipient. At least one report has suggested a decreased rate of rejection with increasing amounts of transfusion in heart transplant recipients previously supported by LVADs. ${ }^{19}$

Interpretation of results from this retrospective study may be difficult for several reasons. Other studies have suggested that sharing of an HLA-DR locus between blood donor and recipient may limit the sensitizing effect and amplify the immunosuppressive effect of transfusion. ${ }^{20} \mathrm{Un}$ fortunately, HLA typing of all blood donors was not available for this study. Other theories suggest that the timing of transfusion is important. Transfusions given intraoperatively, when stress hormones and cytokines are maximal, may be more immunogenic than transfusions given during cytokine quiescence. ${ }^{21}$ This heterogeneous population also includes some debilitated patients who may not be capable of generating an immunologic response at the time of LVAD placement, further confusing the picture. Our attempt to control for the degree of illness with serum bilirubin, a marker of hepatic congestion and long-standing heart failure, showed no difference between groups. Serum bilirubin is a nonspecific marker, however, and may have poor correlation with such an anergic state. Clarification of these issues may not be forthcoming until the true nature, specificity, and time course of the generated antibody have been characterized. Further study of methods to reduce sensitization will likely 
require a prospective approach that can control for these variables. Unfortunately, controlled, prospective trials of this nature would be extremely difficult to perform and may not ever be realistically achieved.

Because this study suggests that sensitization is not worsened by transfusions, the true source of stimulation of antibody production remains in question. Sensitization in LVAD recipients may occur as a result of passenger leukocytes that escape filtration, cytokine activation, or immunogenic stimuli from the pump itself. Antibody stimulated by other sources and cross-reactive to HLA epitopes is known to occur. ${ }^{22} \mathrm{FFP}$, which was received by most patients in this study, may also contain small concentrations of soluble HLA antigen and could have a weak immunizing effect. ${ }^{23}$ Itescu and colleagues ${ }^{24}$ have reported that activated inflammatory cells within the pseudoneointima of the HeartMate textured pumping chamber surface demonstrate augmented expression of the inflammatory mediator nuclear factor $\kappa \mathrm{B}$ and may give rise to increased production of inflammatory cytokines and B-cell hyperreactivity. ${ }^{24}$ This textured surface has been shown to colonize with pluripotent hematopoietic stem cells, which also could become immunologically active. ${ }^{25}$ Schuster and associates ${ }^{26}$ have suggested that exposure of human mononuclear cells to LVAD-derived biomaterial leads to T-cell-dependent B-cell activation through a CD40-CD40 ligand interaction and that treatment with calcineurin inhibitors or monoclonal antibodies against either CD25 or CD40 ligand could be effective at preventing B-cell hyperreactivity and allosensitization. Baran and colleagues ${ }^{27}$ found less sensitization in devices with smooth rather than textured interior surfaces, whereas Kumpati and coworkers ${ }^{28}$ found no difference.

We conclude that sensitization after LVAD placement as bridge to transplantation becomes increasingly prevalent as length of support increases. Perioperative transfusion of leukocyte-filtered cellular blood products does not appear to worsen the incidence or the degree of HLA sensitization in patients who receive LVADs as a bridge to transplantation. Avoiding perioperative transfusions does not protect from and may even worsen allosensitization before transplantation. On the contrary, transfusion may be associated with less sensitization, possibly through immunosuppressive mechanisms. In this era of leukocyte filtration of cellular blood products, other factors may be more important contributors to sensitization of LVAD recipients. Transplantation before sensitization occurs will alleviate the potential emotional and physical toll on LVAD recipients by reducing time waiting and potential LVAD complications, which supports current organ allocation policy. Further study may suggest ways that transfusions can be used as a tool to prevent HLA sensitization and improve outcomes in this challenging patient population.

\section{References}

1. US Organ Procurement and Transplantation Network, US Department of Health and Human Services. 2004 annual report. Washington, DC: US Government Printing Office; 2004. p. 11-9.

2. Frazier OH, Rose EA, Oz MC, Dembitsky W, McCarthy P, Radovancevic $\mathrm{B}$, et al. Multicenter clinical evaluation of the HeartMate vented electric left ventricular assist system in patients awaiting heart transplantation. J Thorac Cardiovasc Surg. 2001;122:1189-95.

3. Massad MG, Cook DJ, Schmitt SK, Smedira NG, McCarthy JF, Vargo RL, et al. Factors influencing HLA sensitization in implantable LVAD recipients. Ann Thorac Surg. 1997;64:1120-5.

4. McKenna DH Jr, Eastlund T, Segall M, Noreen HJ, Park S. HLA alloimmunization in patients requiring ventricular assist device support. J Heart Lung Transplant. 2002;21:1218-24.

5. Smith JD, Danskine AJ, Laylor RM, Rose ML, Yacoub MH. The effect of panel reactive antibodies and the donor specific crossmatch on graft survival after heart and heart-lung transplantation. Transpl Immunol. 1993;1:60-5.

6. Lavee J, Kormos RL, Duquesnoy RJ, Zerbe TR, Armitage JM, Vanek $\mathrm{M}$, et al. Influence of panel-reactive antibody and lymphocytotoxic crossmatch on survival after heart transplantation. J Heart Lung Transplant. 1991;10:921-30.

7. Kobashigawa JA, Sabad A, Drinkwater D, Cogert GA, Moriguchi JD, Kawata N, et al. Pretransplant panel reactive-antibody screens. Are they truly a marker for poor outcome after cardiac transplantation? Circulation. 1996;94(9 Suppl):II294-7.

8. Moazami N, Itescu S, Williams MR, Argenziano M, Weinberg A, Oz MC. Platelet transfusions are associated with the development of anti-major histocompatibility complex class I antibodies in patients with left ventricular assist support. J Heart Lung Transplant. 1998;17: 876-80.

9. Stringham JC, Bull DA, Fuller TC, Kfoury AG, Taylor DO, Renlund DG, et al. Avoidance of cellular blood product transfusions in LVAD recipients does not prevent HLA allosensitization. J Heart Lung Transplant. 1999;18:160-5.

10. John RJ, Lietz K, Burke E, Ankersmit J, Mancini D, Suciu-Foca N, et al. Intravenous immunoglobulin reduces anti-HLA alloreactivity and shortens waiting time to cardiac transplantation in highly sensitized left ventricular assist device recipients. Circulation. 1999;100(19 Suppl):II229-35.

11. Fauchet R, Genetet B, Gueguen M, Leguerrier A, Rioux C, Logeais Y. Transfusion therapy and HLA antibody response in patients undergoing open heart surgery. Transfusion. 1982;22:320-2.

12. The Trial to Reduce Alloimmunization to Platelets Study Group Leukocyte reduction and ultraviolet B irradiation of platelets to prevent alloimmunization and refractoriness to platelet transfusions. N Engl J Med. 1997;337:1861-9.

13. Goldstein DJ, Seldomridge JA, Chen JM, Catanese KA, DeRosa CM, Weimberg AD, et al. Use of aprotinin in LVAD recipients reduces blood loss, blood use, and perioperative mortality. Ann Thorac Surg. 1995;59:1063-8.

14. Banbury MK, Brizzio ME, Rajeswaran J, Lytle BW, Blackstone EH Transfusion increases the risk of postoperative infection after cardiovascular surgery. J Am Coll Surg. 2006;202:131-8.

15. Brand A. Immunologic aspects of blood transfusions. Transplant Immunol. 2002;10:183-90.

16. Claas FH, Roelen DL, van Rood JJ, Brand A. Modulation of the alloimmune response by blood transfusions. Transfus Clin Biol. 2001;8:315-7.

17. Opelz G, Vanrenterghem Y, Kirste G, Gray DW, Horsburgh T, LaChance JG, et al. Prospective evaluation of pretransplant blood transfusions in cadaver kidney recipients. Transplantation. 1997;63:964-7.

18. Wheatley TJ, Veitch PS, Horsburgh ML, Bell PR. Transfusioninduced immunosuppression: abrogation by leukodepletion. Transplant Proc. 1997;29:2962-3.

19. Fernandez FG, Jaramillo A, Ewald G, Rogers J, Pasque MK, Mohanakumar T, et al. Blood transfusions decrease the incidence of acute rejection in cardiac allograft recipients. $J$ Heart Lung Transplant. 2005;24(7 Suppl):S255-61.

20. Lagaaij EL, Hennemann PH, Ruigrok M, DeHann MW, Persijn GG, Termijtelen A, et al. Effect of one-HLA-DR antigen matched and 
completely HLA-DR mismatched blood transfusions on survival of heart and kidney allografts. N Engl J Med. 1989;321:701-5.

21. Bushell A, Karim M, Kingsley CI, Wood KJ. Pretransplant blood transfusion without additional immunotherapy generates $\mathrm{CD} 25^{+} \mathrm{CD} 4^{+}$ regulatory $\mathrm{T}$ cell: a potential explanation for the blood-transfusion effect. Transplantation. 2003;76:449-55.

22. Williams RC Jr, Malone CC, Kao KJ. IgM rheumatoid factors react with human class I HLA molecules. J Immunol. 1996;156:1684-94.

23. Ohto H, Yasuda H, Yokota M, Matsuoka T, Nomizu T. HLA antibodies after transfusions of FFP. Transfusion. 2000;40:613.

24. Itescu S, Ankersmit JH, Kocher AA, Schuster MD. Immunobiology of left ventricular assist devices. Prog Cardiovasc Dis. 2000;43:67-80.

25. Rafii S, Oz MC, Seldomridge JA, Ferris B, Asch AS, Nachman RL, et al. Characterization of hematopoietic cells arising on the textured surface of left ventricular assist devices. Ann Thorac Surg. 1995;60:1627-32.

26. Schuster M, Kicker A, John R, Hoffman M, Ankersmit J, Lietz K, et al. B-cell activation and allosensitization after left ventricular assist device implantation is due to T-cell activation and CD40 ligand expression. Hum Immunol. 2002;63:211-20.

27. Baran DA, Gass AL, Galin ID, Zucker MJ, Arroyo LH, Goldstien DJ, et al. Lack of sensitization and equivalent post-transplant outcomes with the Novacor left ventricular assist device. J Heart Lung Transplant. 2005;24:1886-90.

28. Kumpati GS, Cook DJ, Blackstone EH, Rajeswaran J, Abdo AS, Young JB, et al. HLA sensitization in ventricular assist devices recipients: does type of device make a difference? J Thorac Cardiovasc Surg. 2004;127:1800-7.

Access to The Journal of Thoracic and Cardiovascular Surgery Online is reserved for print subscribers!

Full-text access to The Journal of Thoracic and Cardiovascular Surgery Online is available for all print subscribers. To activate your individual online subscription, please visit The Journal of Thoracic and Cardiovascular Surgery Online, point your browser to http://www.mosby.com/jtcvs, follow the prompts to activate your online access, and follow the instructions. To activate your account, you will need your subscriber account number, which you can find on your mailing label (note: the number of digits in your subscriber account number varies from 6 to 10 ). See the example below in which the subscriber account number has been circled:

\section{Sample mailing label}

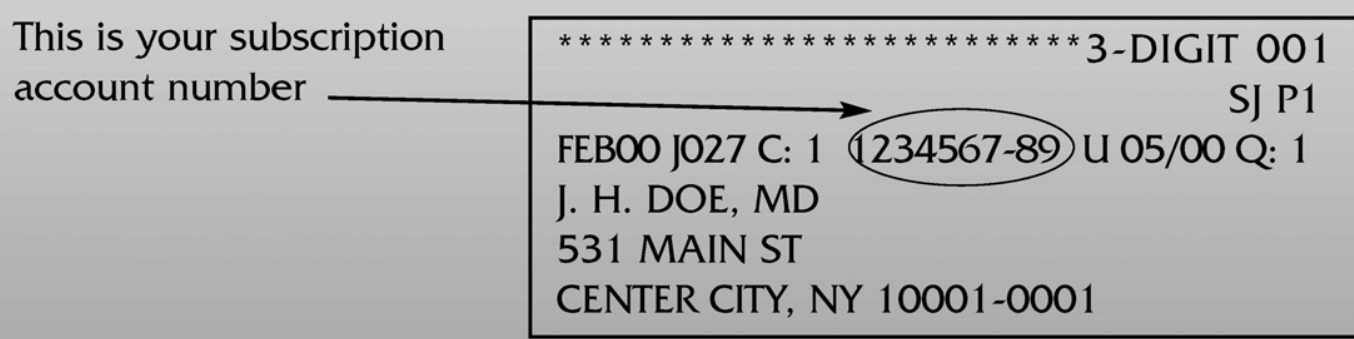

Personal subscriptions to The Journal of Thoracic and Cardiovascular Surgery Online are for individual use only and may not be transferred. Use of The Journal of Thoracic and Cardiovascular Surgery Online is subject to agreement to the terms and conditions as indicated online. 